\title{
Post-2015와 지속가능한 개발을 위한 데이터 혁명
}

제I장

김찬유 (한국국제협력단 연구개발팀 통계전문관)

\section{목 차}

I. 들어가며

II. 데이터 혁명의 정의

III. 국제 원조사회에서의 데이터 혁명 논의

1. Post-2015 개발의제와 데이터 혁명의 등장

2. 데이터 혁명에 대한 국제적인 공감의 확산

3. 지속가능한 개발을 위한 데이터 혁명

IV.Post-2015 시대에서의 데이터 혁명의 역할과 기대효과

1. 데이터 접근성 및 데이터 품질 향상을 통한 효과적인 정책 결정

2. 모니터링 및 평가 강화를 통한 Post-2015 개발의제 달성 기여

3. 원조 투명성 및 책임성 제고

V. 결어: KOICA와 데이터 혁명

1. 체계적인 원조 데이터 관리 및 활용 방안 마련

2. 개발도상국의 데이터 관리 및 통계 역량 강화 지원

\section{I. 들어가며}

오랫동안 기다려왔던 Post-2015 개발의제 확정이 목전에 옴에 따라 그 윤곽이 점차 명확해져 가고 있다. 특히 Post-2015 개발의제의 근간이 될 지속가능개발목표(Sustainable Development Goals, 이하 SDGs)는 17대 목표와 169개의 세부목표를 담고 있으며 따라서 목표를 평가하는 지표 들 또한 304개로 새천년개발목표(Millenium Development Goals, 이하 MDGs)에 비해 대폭 늘어 
날 예정이다. 또한 SDGs는 환경, 불평등, 평화와 안보, 등 기존 $\mathrm{MDGs}$ 에 비해 더욱 광범위하고 다 양한 분야의 개발 목표를 담고 있다. 이는 앞으로 더 많은 원조 데이터가 수집, 관리되어야 함을 의 미한다.

한편, 주목해야 할 점은 SDGs가 모니터링 및 데이터 관리의 중요성을 강조하고 있다는 것이다. 이에 맞추어 향후 SDGs의 데이터 관리 및 원조투명성 제고를 위한 국제사회의 다양한 움직임이 포 착되고 있는데 데이터 혁명(Data Revolution)이 그 대표적인 예이다. 특히, UN지속가능발전해법네 트워크(Sustainable Development Solution Network, 이하 SDSN)는 SDGs의 채택으로 인해 개발 데이터의 중요성을 더욱 증대되고 있으며, 이는 데이터 혁명 추진을 위한 전략적인 기회를 제공한다 고 주장한다(SDSN 2015b, p6).

이러한 국제사회의 노력에 맞추어 국내에서도 관련 논의들이 활발히 이루어지고 있다. 특히 제 18 차 국제개발협력위원회에서 정부 차원의 국제원조투명성기구(International Aid Transparency Initiative, 이하 IATI) 가입을 결정함에 따라 원조투명성에 대한 시민사회의 관심이 뜨거운 상황이 다. KOICA 또한 이러한 정부 시책에 맞추어 2014년부터 IATI 옵저버(observer)로 참여하고 있으며 오는 2015년 9월 기관 차원의 IATI 가입이 예정되어 있다. 이에 따라 현재 KOICA를 비롯하여 관련 정부 기관들은 IATI 기준에 맞춘 데이터 공개 계획을 수립하는 등, 보다 체계적이고 선진화된 데이 터 관리와 원조투명성 제고를 위해 노력하고 있다.

이렇듯 국내외적으로 개발 및 원조 데이터의 질적, 양적 제고와 그 활용에 대한 관심과 필요성이 점증하고 있다. 적절한 원조 및 개발데이터 관리는 원조 투명성 및 효과성 제고에 있어 필수적이기 때문이다. 이에 본고에서는 Post-2015에 대비하여, 데이터 혁명을 중심으로 원조데이터 및 투명성 증진을 위한 국제사회의 동향을 소개하고 이를 바탕으로 $\mathrm{KOICA}$ 에 필요한 시사점 도출 및 향후 대응 방안에 대해 모색해보고자 한다.

따라서 본고는 다음과 같이 구성될 것이다. 제 2 장에서는 데이터 혁명의 정의, 특히 지속가능한 개 발과 관련된 데이터 혁명의 정의를 소개할 것이다. 제 3 장에서는 국제원조사회에서 데이터 혁명과 관 련된 논의와 그 흐름을 살펴볼 것이다. 다음 제4장에서는 Post-2015 시대에서의 데이터 혁명의 역 할과 기대효과에 대해 알아볼 것이다. 이어 마지막 제 5 장에서는 위의 논의들을 바탕으로 지속가능한 개발을 위한 데이터 혁명의 성공적인 이행과 관련하여 원조 공여 기관으로서의 KOICA의 역할과 대 응 방안에 대해 모색해 볼 것이다. 


\section{II. 데이터 혁명의 정의}

데이터 혁명에 대해 명확히 합의된 정의는 아직 존재하지 않는다. 다만 데이터 혁명은 단순한 원 조데이터 관리 및 활용을 넘어 데이터와 관련된 다양한 논의를 포함하는 포괄적인 개념이라 할 수 있 다. 따라서 데이터 혁명은 아래〈 $\mathrm{BOX} 1$ 1)과 같이 데이터와 관련된 다양한 논의들을 다룬다.

\section{제I장}

- 복잡한 개발의제에 대응하기 위한 전환적 조치(transformative action)

- 데이터 생성 및 사용 방법의 개선

- 정보 격차 감소를 통한 차별 방지

- 빅데이터 분석과 정보 해석 능력의 강화

- 데이터 수집의 현대화

- 정보 공개를 통한 투명성 및 책임성 향상

- 새로운 목표 및 지표 개발

* 출처: http://www.undatarevolution.org

위와 같이 데이터 혁명이 데이터와 관련된 광범위한 논의들을 포괄하고 있음에 따라 그 정의 에 대해서도 다양한 의견이 있어 왔다. 이에 따라, 지속가능한 개발을 위한 데이터 혁명에 대한 독 립전문가자문단(Independent Expert Advisory Group on a Data Revolution for Sustainable Development, 이하 IEAG)은 2014년 11월 발간한 보고서 '셀 수 있는 세계: 지속 가능한 발전을 위한 데이터 혁명 동원(A World that Counts: Mobilising the Data Revolution for Sustainable Development)에서 데이터 혁명에 대한 정의를 정리하여 제시하고 있다. 특히 IEAG는 동 보고서에 서 아래와 같이 ‘데이터 혁명’과 ‘지속가능한 개발을 위한 데이터 혁명’을 구분하여 정의하였다.

\section{〈BOX 2〉데이터 혁명과 지속 가능한 개발을 위한 데이터 혁명의 정의}

\begin{tabular}{l|l} 
데이터 혁명 & $\begin{array}{l}\text { - 정보량, 정보생성 속도, 정보 생산자, 정보의 보급, 정보 범위의 팽창 } \\
\text { ・ 사회의 모든 분야에서 정보에 대한 수요 증가 }\end{array}$ \\
\hline $\begin{array}{l}\text { 지속가능한 개발을 } \\
\text { 위한 데이터 혁명 }\end{array}$ & $\begin{array}{l}\text { - 고품질의 정보 생산과 지속 가능한 개발을 촉진하고 모니터링하기 위해 새로운 } \\
\text { 더와 기존 데이터를 통합 공개 증대 및 투명성 향상을 통한 이용 가능한 정보의 증가 } \\
\text { - 인간과 환경에 더 좋은 결과를 도출하기 위해 인력 강화, 좋은 정책과 결정, } \\
\text { 참여와 책임성 향상 }\end{array}$
\end{tabular}

* 출처: IEAG(2014, p6) 바탕으로 저자 재구성 
위와 같이 지속가능한 개발을 위한 데이터 혁명은 개발과 관련된 데이터 혁명을 말한다. 그러므 로 개발 협력 분야에서 지칭하는 데이터 혁명이란 광범위한 데이터 혁명을 뜻하기 보다는 개발 분야 에 초점을 맞춘 데이터 혁명을 뜻한다. 따라서 본고에서 지칭하는 데이터 혁명 또한 개발의 관점에 서 지속가능한 개발을 위한 데이터 혁명을 뜻한다고 할 것이다.

\section{III. 국제 원조사회에서의 데이터 혁명 논의}

\section{Post-2015 개발의제와 데이터 혁명의 등장}

데이터 혁명은 2013년 Post-2015 개발의제를 위한 고위급 패널 회의(High-Level Panel of Eminent Persons on the Post-2015 Development Agenda)의 보고서인 '지속가능한 개발을 통 한 빈곤퇴치와 경제 전환(Eradicate Poverty and Transform Economies through Sustainable Development)'에서 처음 언급되었다. 동 패널 회의는 Post-2015 개발의제 구축을 목적으로 반기 문 UN 사무총장의 요청을 받아 구성되었으며, 수 차례의 회의를 통해 빈곤의 다면성, 포용적 성장 을 위한 경제 전환, 등 Post-2015 개발의제와 관련된 다양한 논의들을 다루었다. 특히 그동안 개 발 성과를 실시간 모니터링하고 관리하기 위한 많은 이니셔티브와 국제적인 노력이 있었음에도 불 구하고 현재의 시스템이 개발 활동들과 그 성과를 충분히 측정하고 있지 못함을 지적하며, Post2015 개발의제를 성공적으로 달성하기 위한 수단으로 엄격한 모니터링 시스템과 함께 데이터 혁명 을 제안하였다.

즉, 지속가능한 개발을 포함한 Post-2015 개발의제의 성공적인 수행은 통계의 질적 제고 및 정 보 접근성 향상을 통해 가능하며 이를 위해 데이터 혁명이 필수적이라는 것이다. 또한 데이터 혁명 을 통해 구축되는 양질의 데이터와 통계는 효과적인 의사 결정과 개발 성과 모니터링의 토대가 될 뿐 만 아니라 나아가 원조 책임성도 향상시킬 수 있다고 역설하였다(UN 2013, p23). 또한 동 보고서는 국제 원조기구, 시민사회단체, 재단, 민간, 등 다양한 이해관계자들이 지속 가능한 개발을 위한 데이 터 혁명에 함께 동참할 것을 촉구하면서 다양한 개발협력 주체들의 협력을 이끌어 내기 위해 '개발데 이터를 위한 글로벌 파트너십(Global Partenership on Development Data)'구축을 제안하기도 하 였다. 나아가 같은 맥락에서 지속가능한 개발을 위해선 정부 뿐 만 아니라 민간 기업들도 기업 활동 이 사회와 환경에 미치는 영향을 보고해야 할 책임이 있음을 강조하였다(Ibid).

위에서 살펴보았듯이, 동 보고서는 Post-2015 개발의제와 관련하여 데이터 혁명이라는 개념을 
처음으로 언급하고 이와 관련된 국제적인 논의를 이끌어내었다는 점에서 의의가 있다. 그러나 논의 의 초점이 Post-2015 개발의제 구축 및 방향 설정이었으며 데이터 혁명은 의제 이행을 위한 수단 으로 제기되었을 뿐이었다. 따라서 데이터 혁명의 필요성에 대해서만 언급했을 뿐 이에 대한 정의나 구체적인 추진 방향 등은 제시하지 못하였다는 한계가 있다. 그러나 Post-2015 개발의제를 주도적 으로 이끌 수 있는 정치적 영향력을 가진 수준에서 데이터 및 통계의 중요성을 강조하고 그 일환으로 ‘데이터 혁명’이라는 구체적인 개념을 도입했다는 점 그리고 이를 위해 다양한 개발 주체들의 참여를 촉구했다는 점에서 의의가 있다고 하겠다.

\section{2. 데이터 혁명에 대한 국제적인 공감의 확산}

사실 국제 원조사회에서 원조 활동의 정확한 모니터링과 데이터 관리의 중요성은 원조투명성 및 효과성과 관련하여 오랫동안 지속적으로 강조되어 온 이슈이다. 따라서 데이터 혁명의 정의나 범위, 등에 대해서는 다소 의견 차이가 있었으나 그 목적과 필요성에 대한 국제적인 합의와 공감은 쉽게 이 루어졌다. 실제로 '지속가능한 개발을 통한 빈곤퇴치와 경제 전환' 보고서에서 데이터 혁명이라는 개 념이 소개된 이후 Post-2015 개발의제 달성을 위해 데이터 혁명을 어떻게 활용할 것인가에 대해 다 양한 논의가 이루어졌다.

그 예로 2014년 1월에 개최되었던 'Post-2015 개발프레임워크를 위한 데이터 및 책무성에 관한 회의를 들 수 있다. 동 회의는 UNDP가 주최하긴 하였지만 시민사회의 주도로 이루어진 회의로 국 제기구 관계자 뿐 만 아니라 관련 NGO 등 다양한 주체가 참여하여 Post-2015 개발의제 달성을 위 한 데이터 혁명과 책임성 강화에 대해 논의하였다. 구체적으로 데이터 혁명의 개념 정의뿐 만 아니 라 빅 데이터, 데이터 혁명을 위한 역량 개발, 데이터 혁명을 위한 다자 이해관계자 파트너십, 정보 공개 및 투명성, 개발도상국의 통계 역량 강화, 등 데이터 혁명과 관련하여 포괄적이고 다양한 이슈 가 다루어졌다. 동 회의는 시민 사회의 주도로 이루어졌기에 국제 원조 사회에 강력한 정치적 영향 력을 행사하기에는 한계가 있었지만, Post-2015 개발의제와 관련해 데이터 혁명의 중요성과 그 필 요성에 대한 시민 사회의 관심과 공감을 보여주었다는 점에서 의의가 있다고 하겠다.

한편, 데이터 혁명에 대한 관심 및 지지는 다양한 CSO 및 NGOs들의 데이터 혁명과 관련된 활 동을 통해서도 알 수 있다. 예를 들어, The centre for Policy Dialogue(CPD), The North-South Institute(NSI) 및 Southern Voice는 'Post-2015 데이터 테스트: 국가 단위에서의 데이터 혁명 분 석(The Post-2015 Data Test: Unpacking the Data Revolution at the Country Level)' 이라는 이니셔티브를 통해 각각 다른 소득 수준을 가진 각 개별국가에서 Post-2015 개발의제와 관련된 데 이터들이 실제적으로 어떻게 수집되고 측정될 수 있는지를 조사하고 있다. 다른 예로, Partnership 
for African Social \& Governance Research(PASGR)는 2013년 3월 Post-2015 데이터 혁명을 주제로 아프리카 포럼을 개최하였다. 동 포럼에서는 특히 아프리카 지역에 초점을 맞추어 데이터 수 집 및 통계 역량 강화, 모니터링, 등 데이터 혁명 관련한 아프리카의 현 상황 및 향후 대응 방안에 대 해 논의하였다. 이렇듯 다양한 원조 관련 시민 단체들은 각 개별 기관 차원의 노력을 넘어 다양한 주 체들과 서로 협력하여 Post-2015 데이터 혁명 지원 및 대응을 위해 노력하고 있다.

한편, 이 외에도 국제기구, 공공 및 민간 분야, 시민 사회, 등 각계각층에서 Post-2015 데이터 혁명과 관련된 다양한 이니셔티브를 창설하고 활동 중에 있다. ${ }^{1)}$ 각각의 이니셔티브들은 빅 데이터, 통계 시스템 현대화, 통계 역량 강화, 오픈 데이터(open data), 등 데이터 혁명과 관련된 다양한 이 슈들을 다루고 있는데, 이러한 각계각층의 움직임들은 데이터 혁명의 필요성과 중요성을 나타낸다고 할 수 있다.

\section{3. 지속가능한 개발을 위한 데이터 혁명}

위에서 살펴보았듯이, 데이터 혁명의 필요성에 대한 국제적인 동의와 요구가 점증함에 따라 반기 문 UN 사무총장은 2014년 8월 IEAG를 설립하고 지속가능한 개발을 위한 데이터 혁명에 대한 자문 및 연구를 요청하였다. Post-2015 개발의제와 관련하여 데이터 혁명의 필요성엔 동의하고 있었지 만, 단체 간 지속 가능한 개발을 위한 데이터 혁명의 개념 및 포괄 범위에 대한 이해 차이가 존재하 는 등 명확히 정리된 기준이 부재했으며 구체화를 위한 논의 또한 필요한 상황이었다. 따라서 이와 같은 요청에 부응하여 IEAG는 2014년 11월 '셀 수 있는 세계: 지속 가능한 개발을 위한 데이터 혁 명 동원(A World that Counts: Mobilising the Data Revolution for Sustainable Development)

1) IEAG의 Data Revolution Group 웹사이트는 Post-2015 데이터 혁명 관련하여 다음과 같이 다양한 이니셔티브들 을 소개하고 있다: United Nations Global Pulse, Global Privacy Enforcement Network, Responsible Data Forum, The International Conference of Data Protection and Privacy Commissioners, Humanitarian Data Exchange(HDX), Partnership on Measuring Information and Communication Technology for Development, Smart Sustainable Development Model(SSDM) Initiative, Connect the World Initiative, High-Level Group for the Modernisation of Statistical Production and Services, Eurostat CROS-Portal page on Big Data Initiative, Paris21 Projcet: Informing a Data Revolution(IDR), Evidence and Data for Gender Equality Initiative, Global strategy to improve agricultural and rural statistics, United Nations Initiative on Global Geospatial Information Management(UN-GGIM), The Statistical Commission Friends of the Chair Group on Broader Measures of Progress, The Post-2015 Data Test, Feasibility study on the use of mobile positioning data for tourism statistics, Producing official statistics with Big Data, International Conference on Big Data for Official Statistics, ABS Big Data Flagship Project, ARC Centre of Excellence for Mathematical and Statistical Frontiers of Big Data Big Models New Insight, data2x, Follow the Money, European Union Open Data Portal, World Bank Open Data portal, Open Data Innovations Network, Open Data for Development, The Open Data Research network, Project Open Data, SDMX - Statistical Data and Metadata Exchange, Nigeria MDG Information System, Data-Pop Alliance, Sustainable Development Solutions Network (http://www.undatarevolution.org/catalog/2/). 
을 발간하였다.

동 보고서에서 IEAG는 데이터 혁명을 ‘의사 결정, 원조책임성 및 개발 과제 해결에 필수적인 데 이터들을 향상시킬 기회라고 소개하며 따라서 각 정부와 UN에게 국가 간, 사람 간, 공공분야와 민 간 분야 간에 존재하는 데이터 접근 및 이용의 격차를 줄여 데이터가 지속 가능한 개발 실현을 위해 사용될 수 있도록 지원해줄 것을 요청하였다(IEAG 2014, p5). 또한 지속 가능한 개발을 위한 데이 터 혁명의 개념 정립과 함께 데이터 혁명이 가져올 기회에 대해 소개하고 있다. 덧붙여, 지속 가능한 개발을 위한 데이터 혁명의 이행과 지원이 시급함을 강조하며 이를 위한 구체적인 제언사항을 다음 과 같이 제시하였다.

아래의 〈Box 3〉에서 제시된 IEAG 제언 사항의 자세한 내용은 다음과 같다. 우선, 원칙과 기준 에 대한 글로벌 컨센서스 구축이란 공공, 민간, 시민분야 등 각 분야의 데이터가 산재적으로 관리되

\section{제I장}

\section{개 \\ 발

제II장

제III장

제IV장 벌 컨센선스'를 구축하고 통일된 기준을 수립하자는 것이다. 둘째, 공공재를 위한 기술과 혁신 공유 란 관련 전문가들이 어떠한 기술 및 혁신이 사용되고 공유될 수 있는지를 논의할 수 있는 '데이터 혁 신 네트워크(Network of Data Innovation Networks)'를 구축하고 이를 통해 모니터링 향상, 효율 성 증대, 협력 강화, 혁신을 위한 인센티브 제공, 등을 촉진시키는 것을 말한다. 셋째, 역량 개발을 위한 새로운 자원이란 데이터 역량 개발을 위해 새로운 재원들이 투자되어야 함을 의미한다. 넷째, 협력과 동원을 위한 리더십과 관련해, IEAG는 지속가능한 개발을 위한 데이터 혁명과 관련된 이니 셔티브 및 기관들이 서로 협력할 수 있도록 UN이 주도하는 '지속가능한 개발 데이터를 위한 글로벌 파트너십' 구축을 제안하고 있다. 마지막으로 SDG 데이터 성과측정과 관련하여서는 최신의 기술과

\section{〈BOX 3〉 지속가능한 개발을 위한 데이터 혁명 실현을 위한 제언}

1. 원칙과 기준에 대한 글로벌 컨센서스 구축

(Develop a global consensus on principles and standards)

2. 공공재를 위한 기술과 혁신 공유

(Share technology and innovations for the common goods)

3. 역량 개발을 위한 새로운 재원 (New sources for capacity development)

4. 협력과 동원을 위한 리더십 (Leadership for coordination and mobilisation)

5. SDG 데이터 관련 빠른 성과 측정

(Exploit some quick wins on SDG data)

* 출처: IEAG(2014, p1-2) 저자 재구성 
도구를 활용하여 SDG 관련 지표나 관련 데이터를 개발, 연구할 수 있는 ‘SDGs 데이터 실험실(SDG Data Lab)'을 설립할 것을 제언하였다.

동 보고서는 데이터 혁명 지원을 목표로 모인 UN의 자문위원단이 작성한 만큼, 국제적인 논의 를 주도할 수 있는 강력한 정치적 리더십을 가진 위치에서 Post-2015에 대비한 데이터 혁명 이행 을 촉구했다는 점에서 의의가 있다. 또한 내용적으로도 지속가능한 개발을 위한 데이터 혁명의 개 념을 정립하고 현실화를 위해 'SDG 데이터 실험실 (SDG Data Lab) 구축', '지속가능한 개발 데이 터를 위한 글로벌 파트너십(Global Partnership for Sustainable Development Data)'과 같은 다 양한 제언사항들을 제시하였다는 점에서도 의미가 있다. 다만, 아직은 논의의 초기단계인 만큼 앞 으로 Post-2015 시대에 IEAG가 지속가능한 개발을 위한 데이터 혁명에 대한 논의를 어떻게 이끌 어나갈지, 또한 어떠한 형태로 IEAG의 제언 사항들이 구체화되어 나갈지에 대해서 지켜보아야 할 것이다.

\section{Post-2015 시대에서의 데이터 혁명의 역할과 기대효과}

데이터 혁명 그 자체가 핑크빛 미래를 보장하는 것은 아니며 오히려 양날의 검으로 작용할 수 있 다. 실제로 IEAG는 데이터 혁명이 가져다 줄 수 있는 기회뿐 만 아니라 위험에 대해서도 함께 소개 하고 있다. 즉, 데이터 혁명은 다양한 종류의 새로운 위험을 가져올 수 있는데 사생활 문제, 부정확 한 데이터로 인한 잘못된 정책 결정, 데이터 접근 및 활용 능력의 격차 증대, 등이 그 예이다. 그러나 데이터 혁명이 올바른 방향으로 진행된다면, 즉 지속가능한 개발을 위한 데이터 혁명이 이루어진다 면 이는 Post-2015 개발의제 달성 및 원조 투명성과 효과성 증진을 이끌 수 있다. 따라서 본 장에서 는 개발에 있어 데이터 혁명의 역할 및 그에 따른 기대효과를 살펴보고자 한다.

\section{1. 데이터 접근성 및 데이터 품질 향상을 통한 효과적인 정책 결정}

개발도상국들의 낮은 데이터 접근성 및 활용도는 개발의 큰 저해 요소로 작용하고 있다. 또한 이는 원조 프로그램의 효과성에도 부정적인 영향을 미친다. 다음 〈표 1〉은 실제로 인간개발지수 (Human Development Index, HDI)와 정보 공개 간의 상관관계에 대해 보여주고 있다.

〈표 1〉을 통해 인간개발지수가 낮은 지역일수록 정보 공개가 잘 이루어지고 있지 않음을 알 수 있다. 특히 시 또는 지역정부 수준의 데이터 공개는 인간개발지수가 매우 높은 지역과 낮은 지역 간 에 거의 20 배 넘는 차이를 보여주고 있다. 더욱 문제는 선진국과 개발도상국 간의 데이터 접근 및 이 
〈표 1〉인간개발지수와 정부 정보 공개 간 관계

\begin{tabular}{c|c|c|c|c|c}
\hline 지역 & $\begin{array}{c}\text { 정보법에 } \\
\text { 대한 권리 }\end{array}$ & $\begin{array}{c}\text { 정부데이터 } \\
\text { 공개 } \\
\text { 이니셔티브 }\end{array}$ & $\begin{array}{c}\text { 시민사회와 } \\
\text { 기술분야 } \\
\text { 전문가로부터의 } \\
\text { 요청 }\end{array}$ & $\begin{array}{c}\text { 정부 데이터 공개 } \\
\text { 이니셔티브를 } \\
\text { 위한 정부의 } \\
\text { 지원 }\end{array}$ & $\begin{array}{c}\text { 시 또는 지역 } \\
\text { 정부 데이터 } \\
\text { 공개 }\end{array}$ \\
\hline $\begin{array}{c}\text { 매우 } \\
\text { 높은지역 }\end{array}$ & 57.81 & 59.69 & 60.31 & 40.28 & 45.14 \\
\hline 높은지역 & 48.75 & 43.13 & 31.88 & 18.06 & 22.22 \\
\hline 보통지역 & 40.00 & 40.91 & 34.55 & 18.18 & 12.12 \\
\hline 낮은지역 & 41.11 & 40.91 & 25.00 & 11.73 & 2.47 \\
\hline 총계 & 49.48 & 44.68 & 42.47 & 25.83 & 25.69 \\
\hline
\end{tabular}

※ 해당지역의 평균값. 점수가 높을수록 좋음.

* 출처: Open Data Institute(ODI) (2013, p11)

제I장

\section{개 \\ 발

용 능력의 격차가 더욱 심화되고 있다는 점이다. 또한 개발도상국 중에서도 가장 개발 상황이 열악 한 아프리카 지역은 다른 지역들보다도 더욱 데이터 공개에 있어 더딘 진행을 보이고 있다(Data for African Development Working Group 2014, p13). 이러한 문제는 지속가능한 개발 실현을 방해 하는 위험 요소가 된다. 따라서 지속가능한 개발을 위한 데이터 혁명은 이러한 격차를 줄이는 혁명 이 되어야 한다. 이는 원조 프로그램과 관련하여 데이터 혁명에 대한 더 많은 관심과 투자가 필요함 을 시사한다.

한편, 효과적인 정책 결정을 위해서는 정보에 근거한 의사 결정이 필수적이다. 물론 여기서 결 정의 근거가 되는 정보는 양질의 그리고 시의 적절한 정보여야 할 것이다. 그러나 〈표 1〉에서 살펴 보았듯이 개발도상국의 경우 정책 결정의 근거가 될 수 있는 데이터 및 이에 대한 정부와 시민사회 의 노력도 절대적으로 부족한 실정이다. 실제로 영국에서 시행한 설문 조사에 따르면 개발도상국 의 공무원들은 데이터 부족으로 인해 최선의 정책 수립이 힘들며 실제로 예산이 어떻게 할당되고 집 행되고 있는지와 같은 정책 운영의 기본적인 부분에서조차 어려움을 겪고 있다고 토로하고 있다. (Stuart E et al, 2015, p17). 한편, 분쟁국의 경우 분쟁발생시 그 기간 동안의 데이터 수집의 불가 능할 뿐 만 아니라 이전의 데이터도 소실되는 이중고를 겪게 된다(Ibid). 나아가 이러한 데이터 부족 혹은 소실은 공여국의 입장에서도 수원국의 니즈에 맞는 적절한 개발 프로그램을 계획하고 관리하는 데 있어 어려움을 유발한다.

높은 수준의 데이터 수집과 이용 능력이 담보될 때 효과적인 정책 혹은 원조 프로그램의 결정이 가능하다. 따라서 데이터 혁명을 통한 수원국의 데이터 수집 및 접근성 강화는 수원국이 높은 품질 의 데이터를 바탕으로 정책을 결정하고 집행할 수 있게 도와줄 수 있다. 실제로 르완다의 경우 데이 
터 수집의 비약적인 발전을 통해 생활 여건 조사, 인구 건강 조사와 같은 주요 통계 지표들의 측정이 가능해졌으며 이를 통해 르완다의 첫 빈곤 감소 전략의 평가가 적시에 이루어질 수 있었을 뿐 만 아 니라 향후 계획 수립도 가능하게 되었다(Staurt et al 2015, p31, Glassman \& Ottenhoof 2014에 서 재인용).

또한 데이터 혁명은 수원국의 정책 결정 뿐 만 아니라 원조 프로그램 계획과 집행에 있어 적절 한 지원이 이루어질 수 있는 근거가 되며 장기적으로 개발 프로그램의 성과 및 목표 달성에 기여할 수 있다. 멕시코의 경우 농가에 제공하는 보조금이 어떻게 제공되고 있는지에 대한 온라인 데이터베 이스 구축 이후 상위 $10 \%$ 의 부유한 농부들이 전체 보조금의 $50 \%$ 를 받고 있는 사실을 알게 되었고, 이를 바탕으로 정부는 해당 정책을 검토 후 보조금을 적절히 재배분 할 수 있게 되었다(UN 2013, $\mathrm{p} 14)$. 즉, 데이터를 통해 지원이 필요한 장소나 대상자를 명확히 하여 집중적인 지원을 할 수 있으며 이는 비용 감소와 함께 프로그램의 효과성도 높일 수 있다.

\section{2. 모니터링 및 평가 강화를 통한 Post-2015 개발의제 달성 기여}

원조 모니터링 및 평가 강화는 Post-2015 개발의제와 관련하여 가장 강조되고 있는 이슈 중 하 나이다. 성공적인 원조 모니터링 및 평가를 위해서는 개발 목표를 측정할 수 있는 적절한 지표 개발 과 관련 데이터 수집은 필수적이다. 이러한 지표 개발 및 데이터 수집은 개개의 원조 프로젝트 뿐 만 아니라 국제사회 원조 전체의 맥락을 아우르는 SDGs 목표 측정까지 아우른다.

앞서 서론에서 언급하였듯이 Post-2015의 토대가 될 지속가능한 개발 목표는 과거 MDGs에 비 해 더욱 광범위하고 다양한 목표들을 담고 있으며 이를 측정할 지표들 또한 대폭 늘어날 예정이다. 또한 반기문 사무총장은 SDGs의 모니터링 및 평가 원칙으로 자발적, 개별 국가 주도적, 참여적, 실 증적, 다층적인 공동평가(universal review)를 내세우며 그 중요성을 더욱 강조하고 있다(김지현 2014, p11). 따라서 Post-2015와 관련하여 국제 원조 사회에서 모니터링과 평가는 앞으로 더욱 큰 축을 차지 할 예정이다.

그러나 정보 통신의 발달로 인해 과거에 비해 엄청난 양의 데이터가 양산되고 있음에도 불구하고 여전히 필요한 데이터 접근 및 수집에 있어 어려움을 겪고 있다. IEAG의 MDGs 데이터분석에 따르 면, 2010년부터 2013년 동안 MDGs와 관련한 55개의 지표와 관련해 얻을 수 있는 데이터는 전체의

2) 다층적인 공동평가 원칙이란 국가-지역-글로벌 차원의 요소를 다루는 평가 원칙 뿐 만 아니라, 다양한 이행주체 가 모여 주제별 도전과제와 병목현상 해결을 논의하는 주제별 평가, 지속가능한 발전을 위한 글로벌 파트너십 자 체를 평가하는 것을 의미한다(김지현 2014, p11-12). 
$60 \%$ 정도에 불과했으며, 가장 높은 수치를 보여준 2005년부터 2009년의 경우에도 $70 \%$ 에 그쳤다 (IEAG 2014, p12). 따라서 SDGs를 성공적으로 이행하기 위해서는 각 목표를 적절히 측정할 수 있 는 지표 개발에 대한 부담과 더불어 늘어난 지표들을 어떻게 모니터링하고 측정할 것인가에 대한 더 많은 노력이 필요하다.

이러한 노력의 예로' Post-2015 Data Test'라는 프로젝트를 들 수 있다. 동 프로젝트는 캐나다, 방글라데시, 세네갈 등 소득 수준이 다양한 7 개의 국가에서 Post-2015의 일부 목표와 관련한 데이 터를 수집해보고 이를 바탕으로 향후 SDGs 데이터 수집의 양과 질 제고를 위한 제언사항을 도출하 는 것을 목표로 하고 있다. (CPD et al., 2014, p.14-15). 이와 같이 광범위한 SDGs의 진행 여부 를 적절하게 측정할 수 있는 지표들이 무엇인지, 그리고 이를 어떠한 방식으로 측정할 것인가에 대 한 논의와 연구는 반드시 필요하다. 그리고 Post-2015 개발 의제의 성공적인 달성을 위해 데이터 혁명이 필요한 이유이기도 하다.

마지막으로 데이터 혁명은 데이터의 수집 방법의 제고도 포함한다. 즉 지속적이고 포용적인 통계 시스템의 구축, 데이터 수집 역량 강화, 최신 기술 도입, 등을 포함한다(Anderson, 2014). 따라서 이러한 노력을 통해 양질의 데이터가 꾸준히 축적된다면 장기적으로 모니터링과 평가 질 제고뿐 만 아니라 비용 감소에 도움이 될 수 있다. 예를 들어 모니터링 단계부터 필요한 데이터가 잘 관리된다 면 프로그램 종료나 사후에 진행되는 평가에 있어 1차 자료(primary data)로 사용될 수 있으며 그 결과 평가 시간 단축 및 데이터 수집의 비용을 줄일 수 있다(Staurt et al 2015, p21). 다른 예로는, 최신의 기술인 SNS를 활용한 모니터링이 있다. 실제로 인도네시아의 UN Pulse Lab 경우 2009년 에서 2012년까지 쌀 가격이 51\%나 폭등함에 따라 소셜 네트워크 서비스인 트위터를 활용하여 식량 안전과 관련된 대화를 모니터링하기도 하였다(Ibid, p43, UN Global Pulse 2014에서 재인용). 이 렇듯 데이터 혁명은 지표 개발, 데이터 수집 개선 등 다양한 방법을 통해 모니터링 및 평가 질 제고 에 긍정적으로 기여한다.

\section{3. 원조 투명성 및 책임성 제고}

데이터 혁명은 원조 투명성과도 밀접한 관련이 있다. 데이터 혁명의 중요한 이슈 중 하나가 데이 터 공개(Open data)이기 때문이다. 즉, 원조 혹은 개발과 관련된 데이터를 수집하는 것에 그치는 것 이 아니라 이를 외부에 공개하고 서로 공유하며 이용하는 것 또한 데이터 혁명의 주요 목표 중 하나 이다. 그리고 이는 결국 원조 투명성 및 책임성과 연관된다. 실제로 최근 원조투명성과 관련해 가장 활발한 활동을 벌이고 있는 IATI의 경우에도 데이터 혁명을 적극 지지하고 있으며 나아가 데이터가 시기적절하고 쉽게 이용 가능한 형태로 제공되어야 함을 강조하는 동시에 이를 위한 국제사회의 노 력을 촉구하고 있다(IATI, 2014, p16). 
한편 데이터 혁명 논의는 수원국 정부나 $\mathrm{NGO}$ 같은 다양한 개발 주체들의 데이터 공개 또한 포함 한다. 그동안 원조 투명성 및 책임성은 공여국 혹은 공여 기관의 활동을 위주로 논의되어 왔다. 원조 투명성의 개념은 기본적으로 원조 수행기관들이 자신의 원조 활동을 외부에 투명하게 공개하는 것 을 말해 왔으며, 이를 통해 책무성과 효과성을 증진시키는 것을 그 목표로 하고 있기 때문이다. 그러 나 2000년대 이후 예산지원(Budget Support) 확대, 등으로 인해 수원국 정부를 통한 원조 집행이 늘면서 수원국의 투명성 강화 또한 강조되고 있다(박수영 \& 박예린 2014, p5). 같은 맥락에서 IATI 의 경우에도 전통적인 국제기구들과 달리 회원 자격을 광범위하게 부여하고 있으며 그 결과 공여국, 수원국 정부기관, 국제기구, $\mathrm{NGO}$ 등 다양한 주체가 참여하여 원조 정보를 공개하고 있다(Ibid, p6). 즉, 공여국과 수원국 모두에게 데이터 공개 및 투명성과 책임성에 대한 요청이 더욱 커져가고 있는 현 상황에서 데이터 혁명의 중요성은 더욱 힘을 얻고 있다.

마지막으로 기억해야 할 점은 단순히 데이터를 공개를 통한 투명성과 책임성 보장이 끝이 아니라 는 것이다. 공개된 데이터를 누구를 위해 그리고 이를 어떻게 활용할 것인지에 대한 논의도 함께 이 루어져야 한다(Ingram, 2014). 단순히 데이터를 공개하는 것만으로는 원조 효과성이 향상될 수 없 기 때문이다. 따라서 공개된 데이터가 실제로 사용되고 널리 활용될 수 있도록 하는 노력도 함께 병 행되어야 하며, 이러한 노력이 병행될 때 데이터 혁명을 통한 지속가능한 개발 또한 실현될 수 있을 것이다.

\section{V. 결어: KOICA와 데이터 혁명}

2015년 9월은 한국의 개발협력에 있어 중요한 달이 될 것으로 보인다. 지난 몇 년간 원조 사회 에서 가장 큰 이슈였던 Post-2015 개발의제가 확정될 뿐 만 아니라, 동 의제가 결정될 Post-2015 정상회의에서 우리 정부의 IATI 가입 계획을 공식적으로 발표할 것이기 때문이다. 이와 더불어 지 속가능한 개발을 위한 데이터 혁명에 관한 국제사회의 관심과 노력은 앞으로도 지속될 것으로 보인 다. 따라서 새로운 개발협력 패러다임에 맞춘 노력이 필요한 시점이다. 따라서 원조 공여기관으로서 $\mathrm{KOICA}$ 의 역할 및 대응 방안을 다음과 같이 생각해 볼 수 있다.

\section{1. 체계적인 원조 데이터 관리 및 활용 방안 마련}

앞서 언급하였듯이 Post-2015의 근간이 될 SDGs의 목표 및 세부 지표가 대폭 늘어남에 따라 데 이터 수집 및 관리가 더욱 중요해질 전망이다. 또한 최근 IATI 설립 등으로 인해 더욱 탄력을 받고 
있는 원조투명성 및 원조효과성 논의는 앞으로 더욱 철저하게 원조 데이터가 관리, 공개되어야 함을 의미한다. 따라서 사업 계획 단계에서부터 보다 철저히 관련된 지표 및 데이터 수집 방안을 마련하 는 한편 선진화된 통계 시스템 구축 및 관리를 통해 수집된 데이터를 더욱 체계적으로 관리하여야 할 것이다. 또한 단순히 데이터를 공개하는 것이 아닌 공개된 데이터들을 적극적으로 활용하고 공유할 수 있는 시스템 마련도 함께 이루어져야 할 것이다.

한편, 위의 시스템 마련이 성공적으로 구축되고 이행되기 위해서는 이를 위한 투자가 중요하다. 실제로 많은 전문가들이 SDGs 모니터링을 위해선 상당한 양의 추가적인 투자가 필요함을 강조하 고 있다(IEAG 2014, p14; SDSN 2015a, p4). 또한 IATI와 관련하여서도, IATI의 기준에 맞추어 새롭게 보고하기 위해서는 단기적인 행정 비용 상승이 불가피함을 인정하고 있다(박수영 \& 박예린 2014, p16). 따라서 전문적인 데이터 관리 인력 확보 및 시스템 구축을 위한 투자가 함께 이루어져 야 할 것이다.

\section{제I장}

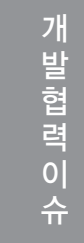

제II장

제III장

제IV장

\section{2. 개발도상국의 데이터 관리 및 통계 역량 강화 지원}

지속가능한 개발을 위한 데이터 혁명은 공여국과 수원국, $\mathrm{NGO,} \mathrm{민간} \mathrm{부문} \mathrm{등} \mathrm{개발과} \mathrm{관련된} \mathrm{다}$ 양한 주체들의 노력을 필요로 한다. 이와 관련해 수원국의 통계 역량 강화와 데이터 공개 관리를 통 한 투명성 및 책임성 강화는 원조효과성 증대와 더불어 지속가능한 개발의 달성을 위해 반드시 필요 하다. 따라서 $\mathrm{KOICA}$ 는 원조 공여기관으로서 수원국의 통계 역량 강화 및 데이터 수집 및 관리 능력 제고를 위한 다양한 사업 개발 및 지원 방안을 마련해야 한다.

또한 프로젝트의 진행 단계에서부터 데이터를 활용하고 수원국과 공유하려는 노력이 필요하다. 이러한 노력을 통해 프로젝트의 성과를 높이는 한편, 수원국의 데이터 관리 능력 역량강화도 함께 이루어질 수 있다. 예를 들어 ODI의 설문조사에 따르면 한 수원국 공무원은 수백만 달러의 예산이 드는 공항 건설을 진행하면서 부족한 데이터로 인해 비용-편익 분석 같은 가장 기초적인 분석조차 이루어지지 않았다고 응답하였다(ODI 2015, p17). 따라서 프로젝트 진행 단계에서도 수원국과 함 께 데이터 수집과 활용 방법들을 공유하려는 노력이 필요하다.

한편, 간접적으로는 프로젝트와 관련된 다양한 조사들, 사전 조사나 혹은 사후 평가에서 이루어 지는 데이터 수집 혹은 활용 또한 수원국의 데이터 역량 강화에 도움이 될 수 있다. 예를 들어, 프로 젝트 평가 진행 시 다양한 통계 기법을 활용하여 프로젝트의 효과성을 측정하게 되는데 평가 과정에 서 진행되는 설문 조사나 통계 프로그램 활용 및 결과 등을 수원국과 공유하고 방법을 생각해 볼 수 있다. 해당 과정에서 얻은 기초 데이터(raw data)들은 해당 프로그램의 성과 측정뿐 만 아니라 향후 수원국이 다른 사업이나 정책 계획 시에도 유용하게 사용될 수 있기 때문이다. 
이렇듯 데이터 혁명은 다양한 부문에서 활용될 수 있다. 또한 수원국의 개발에 기여할 뿐 만 아니 라 $\mathrm{KOICA}$ 의 각종 사업에 있어 원조효과성 향상의 기회를 제공한다. 데이터의 중요성을 기억하고 더 욱 적극적인 활용이 필요한 때이다. 


\section{〈참고문헌〉}

\section{1. 국내문헌}

김지현 (2015). “Post-2015 개발의제 동향연구2: Post-2015 의제에 관한 UN 사무총장 종 합보고서 분석”『개발과 이슈』. 제 22 호. 성남: 한국국제협력단

박수영, 박예린 (2014). “국제개발협력에서 원조투명성 의의분석: IATI와 원조투명성지수를 중심으로”. 개발과 이슈』. 제 18 호. 성남: 한국국제협력단

\section{2. 국외문헌}

Bill Anderson. 2014. “Donors, results, IATI and the data revolution”. Development Initiative. Retrieved from http://devinit.org/old_site/donors-results-iatidata-revolution/

제I장

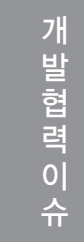

제II장

제III장

Center for Policy Dialogue, The North-South Institute (NSI) and Southern Voice on Post-MDG International Development Goals. 2014. "Methodology and Implementation Guide". Retrieved from http://www.post2015datatest.com/ wp-content/uploads/2014/07/Post2015-Data-Test-Methodology-Guide. pdf

Data for African Working Group. 2014. "Delivering on the data revolution in SubSaharan Africa". Center for Global Development. Retrieved from http:// www. cgdev.org/sites/default/files/CGD14-01\%20complete\%20for\%20 web\%200710.pdf

Glassman, A \& Ottenhoff, J. 2014. "Better data in Rwanda. Center for Global development". Retrieved from http://www.cgdev.org/blog/better-datarwanda

Inagram, G. 2014. "Building aid transparnecy: more data, better data". Retrieved from http://www. publishwhatyoufund.org/updates/by-country/us/ building-aid-transparency-more-data-better-data/

Independent Expert Advisory Group on a Data Revolution for Sustainable Group. 2014. A world that counts: mobilising the data revolution for sustainable development. New York: United Nations.

International Aid Transparency Initiative (IATI). 2014. "Annual Report 2014". Retrieved from http://www.aidtransparency.net/ 
reports/IATI-annual-report-2014.pdf

Open Data Institute. 2013. “Open Data Barometer: 2013 Global Report”. London: ODI. Retrieved from http://www.google.co. kr/url? sa=t\&rct=j\&q=\&esrc=s $\&$ frm $=1 \&$ source=web\&cd $=1 \&$ ved=0CCIQFjAA\&url=http\%3A\%2F\%2Fwww. opendataresearch.org\%2Fdl\%2Fodb2013\%2FOpen-Data-Barometer-2013Global-Report.pdf\&ei=WdSDVaClMoTOmwXRw4GIAQ\&usg=AFQjCNHpJU1 e_7j3HKh8bJ2R3V_Duw6xw\&bvm=bv.96042044,d.dGY\&cad=rjt

Stuart E, Samman E, Abis W \& Berliner B. 2015. "The data revolution: Finding the missing millions". ODI Research Report. London: Overseas Development Institute (ODI).

Sustainable Development Solution Network (SDSN). 2015a. “Data for Development: An Action Plan to Monitor the Sustainable Development Goals and Fulfill the Hopes of the Data Revolution". New York: United Nations.

2015b. "Data for Development: A Needs Assessment for SDG Monitoring and Statistical Capacity Development”. New York: United Nations.

United Nations. 2013. “A New Global Partnership: Eradicate poverty and Transform Economies through Sustainable Development". New York: United Nations.

UN Global Pulse. 2014. "Mining Indonesian Tweets to understand food price crisis". Jakarta: UN Global Pulse. Retrieved from http://www.unglobalpulse.org/ sites/default/files/Global-Pulse-Mining-Indonesian-Tweets-Food-PriceCrises\%20copy.pdf

\section{3. 참고 웹사이트}

Data Revolution Group, http://www. undatarevolution.org Post-2015 Data Test, http://post2015datatest.com

Partnership for African Social and Governance Research(PASGR), http://www.pasgr.org PublishWhatYouFund(PWYF), http://ati. publishwhatyoufund.org 